\title{
Constructing a Comprehensive Learning Style Flexibility Model for the Innovation of an Information Literacy Module
}

\author{
Ann-Louise de Boer, Pieter H du Toit, Theo \\ Bothma, and Detken Scheepers
}

Prof. Ann-Louise de Boer, Professor and Research Fellow, Department of Information Science, Faculty of Humanities, University of Pretoria, Pretoria, South Africa.

Email: ann-louise.deboer@up.ac.za

Dr Pieter H. du Toit, Senior Lecturer, Department of Humanities Education, Faculty of Education, University of Pretoria, Pretoria, South Africa.

Email: pieter.dutoit@up.ac.za

Prof. Theo J.D. Bothma, Professor and Head of Department, Department of Information Science, Faculty of Engineering Built Environment and Information Technology, University of Pretoria, Pretoria, South Africa.

Email: theo.bothma@up.ac.za

Ms. M. Detken Scheepers, Head of e-Learning (Health Sciences), Department for Education Innovation, University of Pretoria, Pretoria, South Africa.

Email: detken.scheepers@up.ac.za

\section{Abstract}

The Department of Information Science in the Faculty of Engineering, Built Environment and Information Technology at the University of Pretoria is responsible for offering a semester module on Information Literacy to all first-year students across all faculties. The Department has embarked on a process of curriculum innovation of the module. For this purpose the learning style theory of Herrmann (1995) and related principles are implemented. At the same time we have expanded the learning style model, referred to as the Whole Brain learning model that Herrmann has developed. We constructed a comprehensive learning style flexibility model or comprehensive whole brain model based on our scholarly engaging with the application of the related principles in numerous contexts. These contexts include our own teaching practices and research and supervision of postgraduate students. The Information Literacy module serves as an exemplar of curriculum innovation based on the concept of learning style flexibility or whole brain learning as it is reflected in our comprehensive model. The model answers the question of how a comprehensive teaching and learning model can be constructed to serve as a guideline for facilitating learning in a learning style flexible/whole brain fashion, accommodating differences in terms of learning preferences and developing students' and lecturers' full potential? The differences in terms of learning preferences referred to in the question were scientifically determined by means of the Herrmann Brain Dominance Instrument (HBDI) (Herrmann 1995). However, the model was not constructed based on this quantitative data only. Through different qualitative methods, such as text analysis, observations, student feedback and interviews, used in different contexts, we as authors extracted from our own work and students' work the ideas that helped shape the model. A constructivist approach was followed as it is embedded in the process of action research.

\section{Introduction}

The Department of Information Science in the Faculty of Engineering, Built Environment and Information Technology at the University of Pretoria is responsible for offering a semester module on Information Literacy to more than 8,000 first-year students across all faculties annually. This figure indicates an increase of about 1,000 students since our initial report on the baseline study of the research project reported in an earlier issue of Libri (De Boer, Bothma, and Du Toit 2011).

A textbook, Navigating Information Literacy: Your Information Society Survival Toolkit (Bothma et al. 2008), written by subject specialists from the Department is used as learning material for the module. The third edition of the textbook (Bothma et al. 2011) is currently in use. Although the module has an acceptable pass rate, the scholarly application of the applicable skills linked to the subject content and learning outcomes is limited and in some cases lacking in subsequent academic years of study. In their endeavour to empower students to develop as lifelong 
learners, the Department introduced a collaborative project entitled: Facilitating Whole Brain Information Literacy: An Interdisciplinary Research Project.

\section{Research Question}

The overarching research question governing the research project is:

How can the principles of whole brain teaching and learning be utilised to innovate the Information Literacy Module offered at the University of Pretoria?

For the purpose of a general understanding of the question addressed in this research, the phrase "whole brain teaching and learning" can be replaced by "learning style flexibility."

The research question can be divided into a number of sub-questions. Typically of the nature of action research that forms the research design of the project, new questions are continuously generated as the research progresses. However, some sub-questions were initially formulated and directed the research. These sub-questions are aligned with specific subprojects. The baseline study is one of the sub-projects. Among others, the following questions were formulated:

What are the learning styles of first-year students?

What are the learning styles of lecturers responsible for teaching the Information Literacy Module?

These two questions are addressed in De Boer et al. (2011) and Du Toit et al. (2010) respectively.

Based on the data generated by means of the baseline studies and our personal experiences in higher education in the field of academic development of both students and academic staff, extending over more than 25 years, the following question is addressed in this article:

What comprehensive teaching and learning model can be constructed to serve as a guideline for facilitating learning in a learning style flexible (whole brain) fashion, accommodating differences in terms of learning preferences and developing students' and lecturers' full potential?

The differences in terms of learning preferences of both lecturers and students implied in the question above were scientifically determined by means of the Herrmann Brain Dominance Instrument (HBDI) (Herrmann 1995). However, the model was not constructed based on this quantitative data only. Through different qualitative methods, such as text analysis, observations, student feedback and interviews, used in different contexts, we as authors extracted from our own work (De Boer and Van Rensburg 1997; De Boer and Van Aardt 1998; De Boer and Steyn 1999; De Boer, Coetzee, and Coetzee 2001; De Boer and Van den Berg 2001; De Boer, Steyn, and Du Toit 2001; Horak, Steyn, and De Boer 2001; Du Toit and Vandeyar 2003; Maree and De Boer 2003; Coetzee, Munro, and De Boer 2004; Du Toit and Van Petegem 2005; Du Toit 2004, 2007, 2008a, 2008b, 2009, 2011) and students' work (Oosthuizen 2001; Voges 2005; Scott 2006; Van der Watt 2008; Von Maltitz 2010; De Jager 2011; Tembe 2011) the ideas that helped shape the model. A constructivist approach as proposed by Burton and Bartlett (2005) was followed as it is embedded in the process of action research.

The many action research projects we were involved in the past have contributed to creating new meaning based on our experience that includes supervising postgraduate studies on learning style flexibility and whole brain learning (Oosthuizen 2001; Voges 2005; Scott 2006; Van der Watt 2008; Von Maltitz 2010; De Jager 2011; Tembe 2011) and what we know from studying relevant literature, publishing about it and presenting papers at national and international conferences (e.g. Du Toit and De Boer 1994; Du Toit 2003, 2007, 2008a, 2008b; Shaker, Du Toit, and Boshoff 2010; Du Toit et al. 2010). Some of the literature studied is reflected in the theoretical framework outlined next. We consider the practice we are engaged in as higher education practitioners (academics) as multidimensional. However, only those learning theories that are key to understanding how we arrived at the comprehensive whole brain teaching and learning model, or comprehensive learning style flexibility model as indicated in the title, are briefly explained. These learning theories and the 
Figure 1. Herrmann Whole Brain mode.

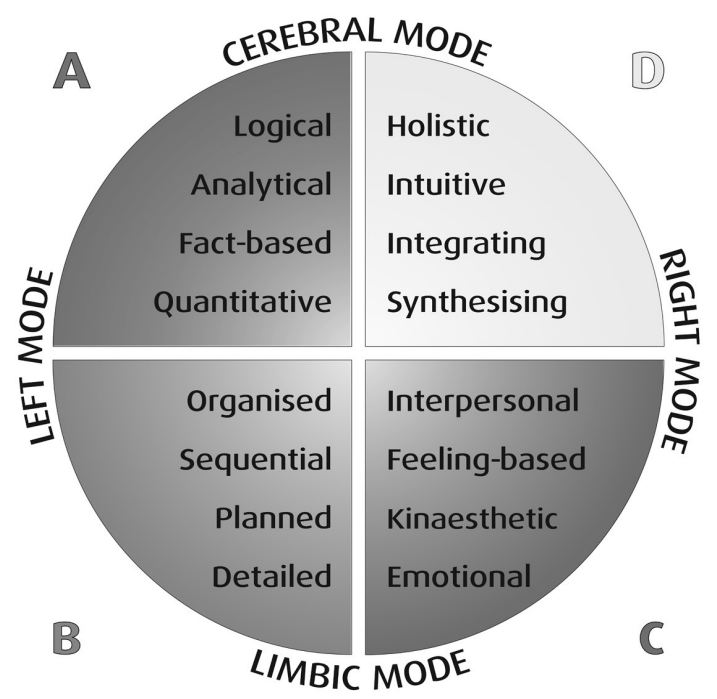

comprehensive model that we propose form the core of our approach to the curriculum development pertaining to the Information Literacy module in question. However, we do not address applicable theories on curriculum development or assessment that are an integral part of our practice and specifically the Information Literacy module.

\section{Background}

Research on the human brain, and specifically on how we think and learn, has contributed to our understanding of the functioning of the brain. Different baseline studies have been conducted in different fields of specialisation at the University of Pretoria pertaining to determining learning styles of lecturers and students. However, the baseline studies that are specifically applicable in the context of this article were in terms of the Information Literacy module in question. The first study was conducted to determine the learning style preferences of first-year students while the second focused on the learning style preferences of lecturers involved in teaching the Information Literacy module and the third on the learning style preferences of the learning material design team. The first baseline study was reported in an article published earlier in Libri (De Boer, Bothma, and Du Toit 2011). The other baseline studies were reported at the 2010 IFLA Conferences respectively (Bothma, Du Toit, and De Boer 2009; Scheepers et al. 2010a; Du Toit, De Boer, and Bothma 2010).

For the purpose of clarity the Herrmann (1996) model is briefly explained next.

In essence the model represents a metaphoric whole brain. It is divided in four quadrants, namely the socalled intellectual self (A quadrant), the safekeeping self (B quadrant), emotional self (C quadrant) and experimental self (D quadrant). The left (structured) mode is categorised by processing dealing with logical, rational, critical, quantitative issues and activities. The procedural, planned, sequential and organised elements of learning activities are found in the structured left mode. Learning of the left mode is depicted in achievements, fact-based knowledge and traditional ways. The experimental right mode is categorised by processing dealing with visual, conceptual, emotional and interpersonal activities. The inclusion of all these modes in learning activities comprises a full and balanced range - as is in general to be found in learning and facilitating learning that are based on the notion of learning style flexibility that we propose. A more detailed explanation of the model is provided in a previous article (De Boer, Bothma, and Du Toit 2011).

The purpose of this article is not to evaluate different learning style theories or models critically but to follow up on the baseline research projects. As follow-up on the baseline studies and other sub-projects that form part of an interdisciplinary study on teaching Information Literacy to the cohort of about 8,000 first-year students annually referred to in the previous section, this article reports a comprehensive model of learning and facilitating learning, using the principles of learning style flexibility (LSF) that resulted as one of the outcomes of several years of research on LSF and whole brain learning by scholars at the University of Pretoria (e.g. De Boer and Van Rensburg 1997; De Boer and Van Aardt 1998; De Boer and Steyn 1999; De Boer and Van den Berg 2001; De Boer, Steyn, and Du Toit 2001; Horak et al. 2001; Du Toit and Vandeyar 2003; Maree and De Boer 2003; Du Toit 2004, 2008a, 2008b, 2011; Du Toit and Van Petegem 2005; De Boer, Bothma, and Du Toit 2011). On the one hand it serves as an instructional design tool that lecturers in all fields of specialisation can use in order to facilitate learning in an innovative way. On the other hand it can be used by students as a learning tool that can assist them in their learning. 
It is especially in the context of self-regulated learning that this model contributes to promoting effective learning and developing the full potential of all involved in learning.

At the centre of the model the most important question that each student and lecturer might like to ask and investigate is: What motivates me? Numerous contributing characteristics of different modes of learning as well as characteristics of those aspects that would be counter-productive to learning are indicated. When referring to learning, two levels of learning are implied: Student learning and the professional learning of the lecturer.

For both the lecturer and the student an intrapersonal locus of control position (Du Toit 2009) should be taken. The lecturer should be a self-motivated learner who would take responsibility for monitoring his/her professional development. When learning becomes the focus of any teaching practice the notion of learning-centeredness (Du Toit 2011) comes alive. The lecturer then considers him-/herself as learning partner.

Since professional learning and therefore the professional development of academic staff involved in the innovation of a module, as is the case in the research project reported, forms the crux of the innovation, it is important to explain our conceptualising of what professional development entails. The definition of Coles (1996) aptly clarifies its meaning for the sake of our study, but we have refined it in order to highlight the value a learning style flexible and action research-driven approach to professional development adds to it: Professional development is concerned with holistic growth, which requires nurturing in an environment, conducive to development, enriched by learning style flexible constructivism and an underpinning interactive process of learning style flexible action research that is practice-focused. Such a process offers professionals the opportunity of learning about practice, with a view to transforming practice in a scholarly manner in collaboration with fellow professionals. Coles $(1996,152)$ continues to indicate that "it involves transformation, sometimes painful, at other times exhilarating, but essentially involving newer insights into one's self and one's engagement with [cutting-edge] practice." The term Coles uses as last part of the quotation is "good practice", but we find this term and the one most scholars use, namely "best practice" to mean "not good enough" and therefore our inserted term.
Our argument in favour of learning style flexibility and self-regulated learning inspired our transforming of the Information Literacy module under discussion.

\section{Theoretical framework}

We appreciate the multidimensional nature of our practices and especially the module on Information Literacy; therefore we acknowledge the fact that a complementary theoretical framework should reflect each practice's subsequent complexity. The interrelatedness of the relevant prominent theories that intersect this field of investigation is addressed and acknowledged. However, within the action research paradigm we follow, we acknowledge the contribution of every action researcher involved in the study regarding constructing new theory.

In essence the theoretical framework revolves around learning style flexibility. The notion of using the principles of learning style flexibility as is to be found in the numerous learning style theories that exist, such as Dunn and Dunn's model and instruments of learning styles, Entwistle's Approaches and Study Skills Inventory for students (ASSIST), Honey and Mumford's Learning Styles Questionnaire (LSQ), Myers-Briggs Type Indicator (MBTI), Sternberg's Thinking Styles Inventory (TSI), Vermunt's Inventory of Learning Styles (ILS) (Coffield et al. 2004) is promoted. All of these theories have one underpinning message: Learning and facilitating learning in different ways as a means to accommodating a preferred style, and challenging students to use other modes of learning. We consider such an approach where a student is challenged to learn in modes beyond his/her comfort zone as the appropriate approach to developing students' full potential - not only accommodating their preferences. For the model that we have developed, based on years of constructivist professional learning we used Herrmann's (1996) theory on whole brain learning. Any other learning style theory and the implementation of its principles, can serve the same purpose. However, learning style theories such as those of Kolb (1984) and Honey and Mumford (1992) have been extensively investigated. Research on whole brain learning per se and specifically in the context of information literacy and the South African context is new. Herrmann's (1996) theory that forms the epicentre of our research is derived from research 
on the human brain as reported by De Boer, Steyn, and Du Toit (2001) and De Boer, Bothma, and Du Toit (2011). Herrmann developed his theory by building a four quadrant model on the notion of left brain-right brain thinking. We have built on his four quadrant model by integrating different ways of facilitating learning, learning preferences, learning avoidances, student expectations and aspects with which students may struggle, all in one comprehensive model. We regard the whole brain model as one that caters for developing the full potential of students and facilitators of learning.

Of the numerous publications on learning/thinking styles by scholars, the recent publication of the socalled Coffield report (Coffield et al. 2004) is the most significant for the purpose of our study. Most of the research done on learning styles in the past was about the learning style instruments per se. Our interest is not in the instruments, but the practical application of the principles applicable to a specific learning style theory. The Coffield report (Coffield et al. 2004), an independent report commissioned through the University of London by the Learning and Skills Council, includes a comprehensive evaluation of learning style theories found in the literature. Coffield and his co-researchers have evaluated in detail 13 of the most influential or potentially influential models, namely Allinson and Hayes' Cognitive Styles Index (CSI), Apter's Motivational Style Profile (MSP), Dunn and Dunn's model and instruments of learning styles, Entwistle's Approaches and Study Skills Inventory for students (ASSIST), Gregorc's Styles Delineator (GSD), Herrmann's Brain Dominance Instrument (HBDI), Honey and Mumford's Learning Styles Questionnaire (LSQ), Jackson's Learning Styles Profiler (LSP), Kolb's Learning Style Inventory (LSI), MyersBriggs Type Indicator (MBTI), Riding's Cognitive Styles Analysis (CSA), Sternberg's Thinking Styles Inventory (TSI), Vermunt's Inventory of Learning Styles (ILS) (Coffield et al. 2004). Their evaluation included inter alia looking at the underlying theory of the model and at empirical constructs such as reliability and validity, as well as pedagogical influence. Only five of these theories were identified as meeting these requirements. The report (Coffield et al. 2004) concludes that Herrmann's whole brain model and instrument, the Herrmann Brain Dominance Instrument (HBDI) are one of the five recommended models, with its applicable instrument, in education and training. The report indicates that the model is especially of use because it throws light on group dynamics and encourages awareness and understanding of self and others. With this in mind, and with the acknowledgement of a term such as learning style flexibility (LSF), we see our application as relevant to all other learning style theories.

The Herrmann model not only identifies a high preference for a specific mode of thinking/learning but also a low preference for other modes of thinking. This is perhaps the most significant in terms of learning effectiveness and all learning style theories since the key to excellence in facilitating learning is to find appropriate strategies to address those low preferences - some of which may be essential to success in a particular subject. Apart from the empirical accountability of the theory, we consider the model as holistic and user-friendly and therefore it has become our learning style model of choice.

No single adult learning theory can be implemented to address all challenges lecturers face on a daily basis in their practices. However, LSF has become the underpinning theoretical basis for our considering of other related learning theories. Whenever a learning theory comes into play in our practices we integrate our understanding of learning style flexibility with the principles of the applicable theory. Action learning as explained by Kember (cited by Zimmerman, Bonner, and Kovach 1996) that entails all the principles of self-regulated learning and includes critical reflection becomes, when integrated with LSF, learning style flexible action learning; critical reflection becomes learning style flexible reflection. As we link the principles of whole brain learning (Herrmann 1996) with other learning theories, the same can be done with other learning style theories such as Kolb's (1984) experiential learning model. For example, when integrated with the theory on self-regulated learning, one might like to refer to the fact that a self-regulated learner should use all stages of Kolb's learning model, namely concrete experience, reflective observation, abstract conceptualisation and active experimentation in order to become flexible in terms of learning with a view to adapting to the nature of the task at hand. Therefore, one would like to see students develop as flexible learners who would be able to act as assimilators, accommodators, convergers and divergers, each with its preferences and dislikes - as part of developing their full potential.

Developing the full potential of first-year students enrolled for the Information Literacy module in ques- 
tion, is one of the objectives of our application of the principles of LSF. The lecturers responsible for teaching the module were challenged to adapt their preferred styles in order to accommodate the different learning styles. Apart from the initiative taken by these lecturers to become innovative the learning material design team took responsibility for adapting the PowerPoint slides and learning activities that are generally used by all lecturers and that serve as a toolkit from which the lecturer can select.

Linking LSF and the theory on Multiple Intelligences (Gardner 1993) is evident in the fact that each intelligence can be aligned with different learning styles. In terms of whole brain learning each of the intelligences can be aligned with each of the quadrants in which its dominance resides. For example, interpersonal, intrapersonal and musical intelligence are dominant in the $\mathrm{C}$ quadrant that favours emotive thinking; logical-mathematical intelligence is typical of the A quadrant. We would like to claim that all other adult learning theories applicable in the university context, such as co-operative learning, be considered as learning style flexible as we would refer to learning style flexible co-operative learning, learning style flexible constructivist learning, etcetera.

For our reading on co-operative learning we studied, inter alia, the work of Johnson and Johnson (1990); for our conceptualising of constructivist learning we studied the work of Von Glasersfeld (2001). However, it is not the purpose of this article to go into the detail of all these theories. What would be significant though is to highlight the research conducted on learning style flexibility and whole brain learning at the University of Pretoria that specifically focuses on facilitating learning in a variety of higher and adult education contexts that we supervised briefly.

Groundbreaking work in this regard is the study by Oosthuizen (2001). He applied the principles of LSF in his teaching practice as lecturer in Tooth Morphology. The significance of the study is in the innovative approach taken to offering the applicable module to fourth-year dentistry students. Apart from the significant increase in the pass rate (which we acknowledge cannot be ascribed to one single variable) the creative work of these students is of significance. It is clear in the outcome of some of the assignments that the students were accommodated according to their different learning styles. They were offered the choice of working as individuals or as a group. Products such as a clinical jacket being painted by a group, games such as Tootholopoly and Odontoquiz designed by groups, an in-flight magazine by an individual and a CD recording of a song written by a student are remarkable examples and evidence of what can be achieved.

Scott (2006) made a significant contribution to the scholarship of LSF. The focus of her study is on adult learning within the context of the professional development of ministers in the Church of the Nazarene in Mozambique. Within the framework of holistic learning LSF is included as key theory. The significance of this study is the rural context in which the principles of LSF are implemented. LSF in this study is juxtaposed with the study above that is operationalised in a sophisticated first world context.

A study by Van der Watt (2008) investigates the significance of LSF in the context of the professional development of health science practitioners. Her focus was on radiologists. The principles of LSF and portfolio building that includes critical reflection show how different learning theories are integrated to the background of a learning style flexible approach. As part of her investigation the idea of LSF in terms of critical reflection was conceptualised.

Voges (2005) took up the challenge to introduce LSF as an innovation to a very traditional training context, where change is not easily embraced, namely the military. Due to the restricted nature of the study, detail on the implementation and the outcome of the HBDIs for a representative group, are limited. However, in her conclusion the researcher indicates the empowering effect the introducing of LSF had on the specific group and within the wider military training community.

Within the context of peer mentoring, two researchers, namely De Jager (2011) and Tembe (2011) approached their respective mentoring practices from a LSF perspective. Both applied LSF as strategy for mentoring - breaking the ground in terms of introducing learning style flexible mentoring as a new construct. Their research and our supervising the projects set the scene for us to build on our constructivist process of informing our living theories (McNiff and Whitehead 2006) and our practice theories (Korthagen 2001) that have become our enriched pedagogy.

Current studies we are involved in focus on implementing the principles of LSF in the Department of Family Medicine in the Faculty of Health Sciences, the Department of Taxation in the Faculty of Economic and Management Sciences and the Department of 
Figure 2. Comprehensive whole brain model of facilitating learning accommodating diverse thinking preferences .

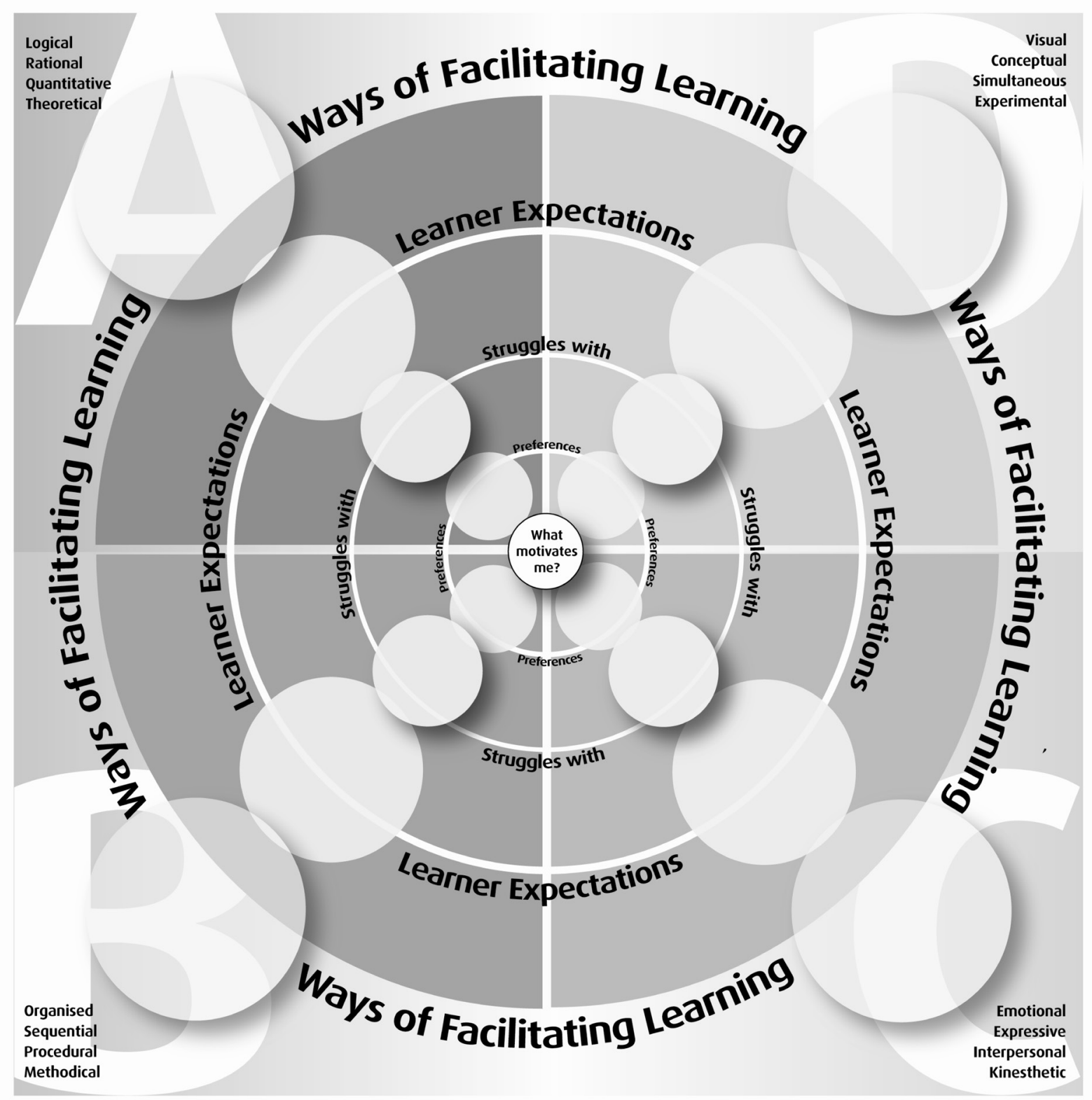

Mining Engineering in the Faculty of Engineering, Built Environment and Information Technology.

Most of the exemplars reported above are based on action research studies. Since action research is a constructivist approach to professional learning, new theory has been constructed in the different contexts. We therefore consider the process as learning style flexible constructivism; moreover, we consider learning style flexible action research (Du Toit 2009) as an appropriate approach to professional learning and as an essential theory.

\section{Research design}

The action research approach we adopted is typical of an asset-based approach (Du Toit 2009). Using LSF and the fact that all participants know their learning style profile are considered an asset and point of departure for constructing new meaning. The constructivist nature of the process we follow allows us constantly to look at what we are busy doing in a scholarly manner. This implies that we construct new meaning based on what we read and what we experi- 
ence. Heylighen (1997) points out that constructivist epistemology holds that knowledge is not passively received but it is actively constructed by the individual through interactions with the environment, which includes other individuals. The environment informing our constructing of meaning is the higher education landscape that includes, inter alia, our involvement in curriculum development activities, facilitating learning and our research projects. In the context of the research reported in this article we came to a defined understanding of the application of the principles of LSF when teaching Information Literacy.

Through our experience of being involved in some way or another in the studies on LSF and whole brain learning conducted at the University of Pretoria and our implementation of the principles of LSF in our own teaching practices and through researching LSF as unit of analysis (specifically in Information Literacy) and presenting numerous workshops on LSF, we have been able to integrate our newly constructed meaning. This integration has resulted in a comprehensive new LSF model designed as a tool for both students and lecturers. However, since we base our model on Herrmann's (1996) work, we call it a comprehensive whole brain model. Any scholar of learning style theories and implementation of the related principles might like to consider it as a model that can be adapted for any such theory. Therefore it could be seen as a comprehensive LSF model.

This article describes how our comprehensive learning style flexible/whole brain model based on the work of Herrmann $(1995,1996)$ as originator of the idea can be used as a tool to combat classroom challenges and assist lecturers in designing innovative learning opportunities, taking into account the thinking preferences of both the student and the facilitator of learning. This is exactly what we did to transform the Information Literacy module in question.

Firstly an outline of the comprehensive model as visually represented in Figure 2 is given. Subsequent to this a breakdown of each quadrant of the model is represented in figures 3 to 6 and briefly explained.

Figure 2 is a one-dimensional overview of the diverse ways individuals prefer to think, learn and do, areas they struggle with and ways to facilitate learning based on the principles of learning style flexibility. The specific terminology used is derived from the Herrmann $(1995,1996)$ whole brain model. The comprehensive learning style flexibility model is our contribution to the body of knowledge on learning styles.
We wish to honour the great mind behind the model, namely Ned Herrmann - therefore the reference to "comprehensive whole brain model" and the use of typical Herrmannian words. The HBDI is patented, as is the case with other learning style questionnaires. We are therefore mindful of the fact that as practitioners and scholars our practices and research respectively should promote the concept of learning style flexibility in general. That is exactly what this article intends to do.

The model not only represents the differences in terms of the nature of content (the 'what') but also the ways of knowing or the learning process (the 'how'). Both the content and learning process should be considered when being involved in the design and development of curricula, educational activities or learning material. These educational aspects should take into account the expectations as well as areas of lesser preference. If we use innovative ways in facilitating learning, not only will we most probably accommodate students' diverse thinking preferences but we will also activate those areas of lesser preference the so-called areas of avoidance. Challenging students to develop skills, constructing new knowledge, new attitudes and values (collectively new meaning) in those least preferred areas might ultimately develop students into well-rounded citizens that can contribute to the community they serve in innovative ways: taking a leadership position.

In their design and delivery of key learning points learning activities and tasks should ideally be designed to move back and forth dynamically across all four quadrants of the whole brain model - ensuring learning style flexibility. Using the model in Figure 2 starting in the centre the model places emphasis on what motivates the individual (student or lecturer). It also indicates the areas of lesser preference (or multiple modes) that might turn off the individual. Therefore the individual will probably struggle with that specific mode.

In order for effective learning to take place students need to be 'turned on' by lecturers in their preferred modes, keeping in mind that a classroom represents a whole brain (De Boer, Bothma, and Du Toit 2011) and need to be empowered to develop thinking skills in their least preferred modes, using their most preferred modes. All four brain quadrants should be included in teaching and learning activities as Steyn (1998) and Steyn and De Boer (1998) point out that cognitive functions are used when learning activities 
Figure 3: Left cerebral mode (A quadrant).

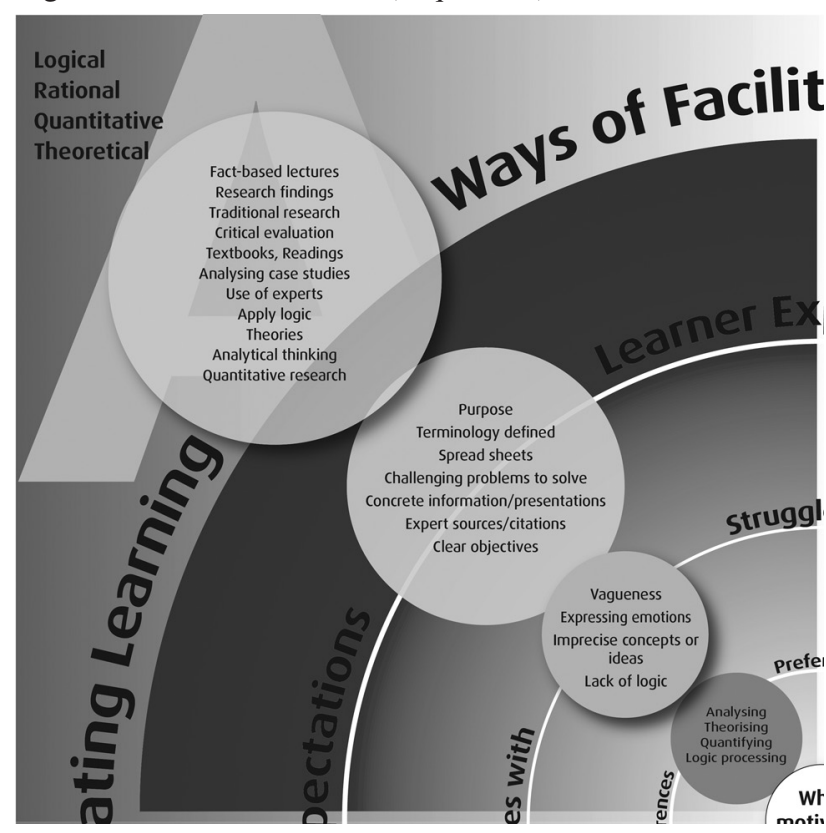

are constructed in such a way that the cognitive functions associated with all four quadrants of the Herrmann model are used.

Complementing Figures 3, 4, 5, and 6, the quadrants are next discussed in more detail. The discussion highlights student expectations, areas in which students most probably will struggle and outlines ways of facilitating learning. The entire discussion reflects our own interpretation and integration and has not been published in the work of Herrmann or elsewhere. The reader should take note of the examples that are offered in the respective circles although not discussed individually.

The A quadrant reflects a strong preference for thinking analytically, logically and for quantifying. The areas in which students with a preference for this way of learning/doing might find it more difficult to work, are dealing with issues that are not logical or that are vague, imprecise concepts or ideas, expressing emotions. They prefer to work as individuals and not in groups and prefer challenging problems to solve, where the purpose of the project and the objectives are spelt out.

The best way to get their attention in a learning environment is the traditional way of teaching - factbased lectures and presentations of well researched topics. Lecturers who prefer this mode of doing might prefer to design learning opportunities that are based on well researched topics that reflect logical
Figure 4. Left limbic mode (B quadrant) .

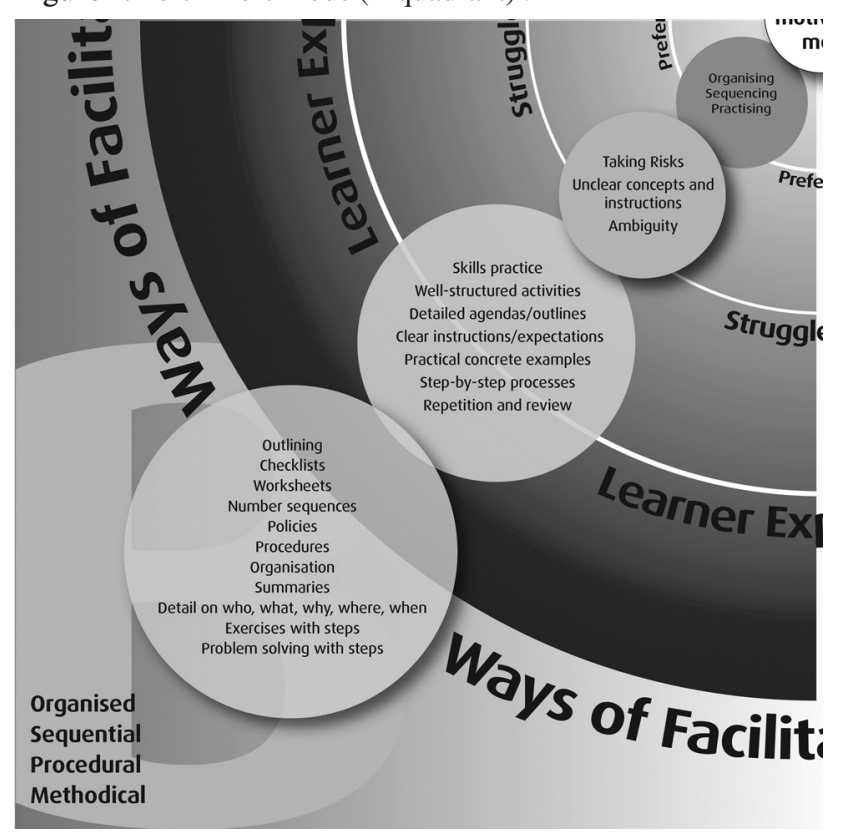

argumentation and deal with quantifiable evidence. Such a lecturer might find it difficult when students provide vague answers and might avoid making use of group work.

The B quadrant displays a strong preference for controlled, structured, and organised thinking modes. Students who prefer these modes of thinking/doing might prefer to be involved in well structured learning activities and to have an opportunity for practising new skills. However, they might struggle in an environment that does not embrace order and structure.

The best way for a lecturer to get their attention during a learning opportunity might be to give detailed lectures - explaining the who, what, when and where, summarising key points on a regular basis, offering the session in a step-by-step fashion, followed by checklists ensuring them all the time that they are on the right track. All of these most probably will add to their experience of feeling safe.

For the lecturer who would equally like to experience the feeling of being safe, since he or she might have a preference for learning according to this quadrant, it most probably would be easy to design structured learning opportunities. However, he or she might be looking for detailed answers and would like to manage a group of students in a firm way.

What motivates those with a $\mathrm{C}$ quadrant preference is being involved and sharing experiences with others. Individuals with a preference in this quad- 
Figure 5. Lower limbic mode (C quadrant).

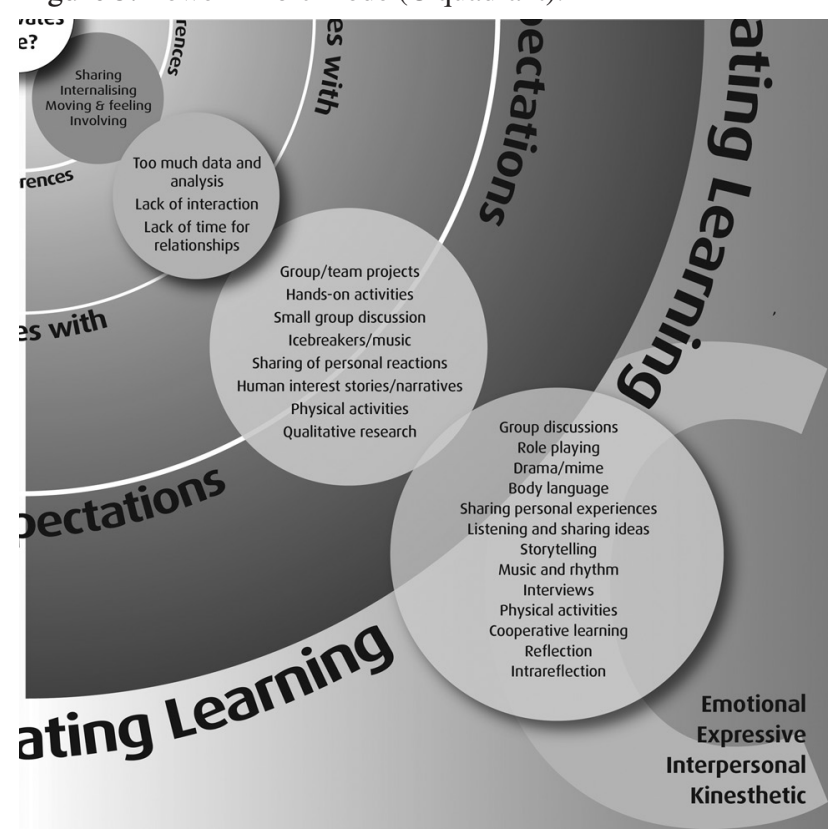

rant prefer to work in groups, enjoy team efforts and hands-on activities. They therefore struggle with data overload, analysis and a lack of interaction or time for expressing ideas.

The best way to get the most out of these individuals is group discussions, time to reflect on the content, for example, to express these reflections and to share personal experiences and stories, as well as role play.

A lecturer that shows a preference for this quadrant would most likely plan for co-operative learning groups, oral presentations and activities in which students can reflect on their learning experiences and share their reflection with others.

Figure 6 represents the upper cerebral or D quadrant mode of thinking. A preference for this mode of thinking is holistic and involves the big picture. Students with this preference are imaginative, conceptual, do not want detail. Individuals who have a preference for this mode thrive on discovery, experimenting, synthesising parts into a new concept. They prefer having the freedom to think about innovative ideas in solving problems, making visual illustrations and using mental imagery. They do not enjoy the traditional way of teaching. The best way to motivate these individuals is to allow for brainstorming sessions, getting new ideas to make things better, to play games or to draw mind maps.

Lecturers who fall within this mode of thinking and doing are usually considered innovative, but may
Figure 6. Upper cerebral mode (D quadrant).

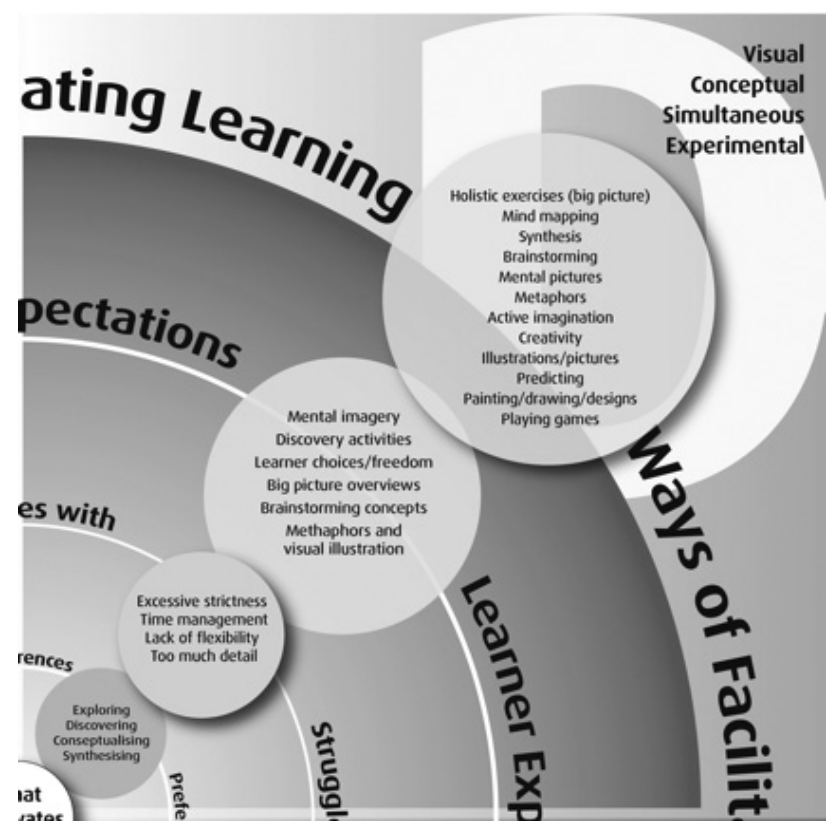

come across as being unstructured and disorganised.

\section{Conclusion}

Felder $(1996,18)$ states the following:

If professors teach exclusively in a manner that favors their students' less preferred learning style modes, the students' discomfort level may be great enough to interfere with their learning. On the other hand, if professors teach exclusively in their students' preferred modes, the students may not develop the mental dexterity they need to reach their potential for achievement in school [university].

His observations that successful educational activities that implement different modes of learning will ensure that students' preferred thinking styles are accommodated and less preferred thinking modes are utilised as well, are supported in our research.

The comprehensive model presented is the outcome of many years of involvement in teaching in a LSF mode or the whole brain manner, researching LSF and whole brain learning, supervising research on the topic and offering workshops on it. As a comprehensive learning style flexibility model the model 
proposed serves as an exemplar of how most other learning style theories/models can be developed.

We specifically propose the model for implementing during the facilitating of information literacy. Information per se can be aligned with the different quadrants based on the nature of the information, since some information is fact-based (A quadrant), some comes in a structured format (B quadrant), some is filled with emotions ( $\mathrm{C}$ quadrant), or is visual and gives the bigger picture (D quadrant). Information is also used and managed according to these quadrants, since the end-user has a specific thinking preference that will inform one's use and managing of information. Therefore the curriculum innovation of the Information Literacy module in question is based on the principles of learning style flexibility/whole brain learning. By applying learning style flexibility to the Information Literacy module it serves as an exemplar of innovation and cutting-edge practice that can be adapted to any programme or module.

\section{References}

Bothma, T. J. D., E. Cosijn, I. Fourie, and C. Penzhorn. 2008. Navigating Information Literacy: Your Information Society Survival Toolkit. 2nd ed. Cape Town: Pearson Education South Africa.

Bothma, T. J. D., E Cosijn, I. Fourie, and C. Penzhorn. 2011. Navigating Information Literacy: Your Information Society Survival Toolkit. 3rd ed. Cape Town: Pearson Education South Africa.

Bothma, T., P. H. Du Toit, and A-L. De Boer. 2010. "Whole Brain Continuing Professional Development of Academic Staff Involved in Facilitating Information Literacy." Paper presented at the $75^{\text {th }}$ IFLA General Conference and Assembly, Libraries create futures: Building on cultural heritage, 23-27 August, Milan, Italy.

Burton, D., and S. Bartlett. 2005. Practitioner Research for Teachers. London: Paul Chapman Publishing.

Coetzee, M-H, M. Munro, and A. De Boer. 2004. "Deeper Sites Through Various Lines: LMS and Whole-Brain Learning in Body/Voice Training for Performers in the HET Band." South African Theatre Journal 18: 135-158.

Coffield, F., D. Moseley, E. Hall, and K. Ecclestone. 2004. Learning Styles and Pedagogy in Post-16 Learning. A Systematic and Critical Review. London: Learning and Skills Research Centre.

Coles, C. 1996. “Approaching Professional Development.” Journal of Continuing Education in the Health Professions 16 (3): 152-158.

De Boer, A., T. Bothma, and P. H. Du Toit. 2011. "Enhancing Information Literacy through the Application of Whole Brain Strategies." Libri 61 (1, March): 67-75.

De Boer, A., H. S. Coetzee, and H. Coetzee. 2001. “Teaching Cataloguing and Classification at the University of Pretoria:
Thinking Preferences of Second Year Students.” Libri 51 (2, June): 63-71.

De Boer, A., and T. M. Steyn. 1999. “Thinking Style Preferences of Under Prepared First Year Students in the Natural Sciences." South African Journal of Ethnology 22 (3): 97-102.

De Boer, A., T. Steyn, and P. H. Du Toit. 2001. "A Whole Brain Approach to Teaching and Learning in Higher Education." South African Journal of Higher Education 15 (3): 185-193.

De Boer, A., and C. Van Aardt. 1998. "Project Initiative 2100 - a Development Programme: Findings and Insights." South African Journal of Ethnology 21 (2): 55-59.

De Boer, A., and D. Van den Berg. 2001. "Challenges to Facilitate Effective Teaching and Learning of Criminology: The Four Quadrant Whole Brain Approach.” Acta Criminologica South African Journal of Criminology 14 (1): 111-121.

De Boer, A., and M. C. J. Van Rensburg. 1997. "Underprepared Students in the Faculty of Arts: Burden or Boon? A Preliminary Report." South African Journal of Ethnology 20 (4): 59164.

De Jager, T. 2011. "Beginner-Teacher Professional Development: An Action Research Approach to Mentoring." MEd dissertation, University of Pretoria.

Du Toit, P. H. 2001. "Matching Learning Styles and Portfolio Development in Teacher Education in the Context of Multiple Intelligences." Paper presented at the Multiple Intelligence Conference, 21 June, Hong Kong Baptist University, Hong Kong.

Du Toit, P. H. 2003. "Matching Action Research and Learning Style Flexibility." Paper presented at the ALARPM 6th and PAR 10th World Congress: Learning Partners in Action, 21 24 September, University of Pretoria, Pretoria.

Du Toit, P. H. 2004. "Learning Styles." In Keys to Education Psychology, edited by I. Eloff and L. Ebersöhn, 145-163. Cape Town: UCT Press.

Du Toit, P. H. 2007. "Learning Style Flexible Action Research." Paper presented at the Trade Conferences International Conference: Transforming Higher Education South Africa, 78 March, Indaba Hotel, Fourways Johannesburg.

Du Toit, P. H. 2008a. "Learning Style Flexible Assessment." In Outcomes-based Assessment, edited by J. G. Maree and W. J. Fraser, 49-61. Sandown: Heinemann.

Du Toit, P. H. 2008b. "Matching Learning Style Flexibility and Action Research for Academic Staff Development." Paper presented at the Annual AERA (American Educational Research Association) Annual meeting: Research on Schools, Neighborhoods, and Communities, 24-28 March, New York.

Du Toit, P. H. 2009. An Action Research Approach to Monitoring One's Professional Development as Manager. Pretoria: Foundation for Professional Development.

Du Toit, P. H. 2011. Reader for Postgraduate Studies in Professional Development, Facilitating Learning and Assessment. Pretoria: University of Pretoria.

Du Toit, P. H., T. Bothma, A. De Boer, I. Fourie, and D. Scheepers. 2011. "From Creativity to Innovation to Transformation in Information Literacy for University Students: Learning Material that Makes a Difference." Paper presented at the 7th Librarians' Information Literacy Annual Conference (LILAC), 18-20 April, London.

Du Toit, P. H., and A. De Boer. 1994. "The Role of Learning Styles in the Dynamic Teaching of Management Sciences.” Paper pre- 
sented at the 6th Annual Conference of the Southern African Institute for Management Sciences (SAIMS): The Economic and Management Sciences - Priorities and Contemporary Issues, 5-6 September, University of the Western Cape.

Du Toit, P. H., A. De Boer, and T. Bothma. 2010. "A Whole Brain Approach to Greening Human Capital - The Multiple Colours of Green." Paper presented at the International Conference on Human Capital for Sustainable Economics: Greening Human Capital - Creativity and Innovation, 27-28 May, Karlsruhe, Germany.

Du Toit, P. H., A. De Boer, T. Bothma, and D. Scheepers. 2010. "Multidisciplinary Collaboration: A Necessity for Curriculum Innovation." Paper presented at the IFLA Pre-Conference: Open Access to Knowledge - Promoting Sustainable Progress, 10-15 August, Gothenburg, Sweden.

Du Toit, P. H. and S. Vandeyar. 2003. "Innovative Portfolio Assessment - Portfolios as Performance Assessment Tool." In Outcomes-based Assessment edited by J. G. Maree and W .J. Fraser, 120-141. Sandown: Heinemann.

Du Toit, P. H. and P. Van Petegem. 2006. "Learning Style Flexibility for Virtual Teams.” In Teaching and Learning with Virtual Teams, edited by S. P. Perris and S. Godar, 32-52. Hershey, PA: Information Science Publishing.

Felder, R. 1996. "Matters of Style." ASEE Prism 6 (4, December): $18-23$.

Gardner, H. 1993. Frames of Mind: The Theory of Multiple Intelligences. 2nd ed. London: Fontana Press.

Herrmann, N. 1995. The Creative Brain. 2nd ed. Kingsport, TN: Quebecor Printing Book Group.

Herrmann, N. 1996. The Whole Brain Business Book. New York: McGraw-Hill.

Heylighen, A. 1997. “Epistemological Constructivism.” Accessed March 15, 2007. http://pespmc1.vub.ac.be/CONSTRUC.html.

Honey, P., and A. Mumford. 1992. The Manual of Learning Styles. Maidenhead, UK: Peter Honey Publications.

Horak, E., T. M. Steyn, and A. De Boer. 2001. "Thinking Style Preference for Engineering Students." South African Journal of Higher Education 15 (3): 202-209.

Johnson, D. W., and R. T. Johnson. 1990. "Using Cooperative Learning in Mathematics." In Cooperative Learning in Mathematics, edited by N. Davidson, 103-125. San Francisco, CA: Addison Wesley.

Kember, D. 1996. "The intention to both memorise and unterstand: Another approach to learning?" Higher Education 31: 341-351.

Kolb, D. A. 1984. Experiential Learning: Experience as the Source of Learning and Development. Englewood Cliffs, NJ: Prentice Hall.

Korthagen, F. A. J. 2001. Linking Practice to Theory: The Pedagogy of Realistic Teacher Education. Mahwah, NJ: Lawrence Erlbaum Associates.

Maree, J. G., and A. De Boer. 2003. "Assessment of Thinking Style Preferences and Language Proficiency for South Afri- can Students Whose Native Languages Differ." Psychological Reports 93 (2): 449-457.

McNiff, J., and J. Whitehead. 2006. All You Need to Know about Action Research. London: Sage Publications.

Oosthuizen, M. 2001. "An Investigation into Facilitating Learning via the Whole Brain Model in the Study Unit Tooth Morphology." MEd dissertation, University of Pretoria.

Scheepers D., A-L. De Boer, T. Bothma, and P. H. Du Toit. 2010. "A Mental Model for Successful Interdisciplinary Collaboration and Co-Operation in Curriculum Innovation for Information Literacy." Poster presented at the IFLA-ALISE-EUCLID Satellite Meeting of the IFLA Conference, 8-9 August, Boras, Sweden.

Scott, M. 2006. "The Efficacy of Holistic Learning Strategies in the Development of Church Leaders in Mozambique: An Action Research Approach." PhD thesis, University of Pretoria.

Shaker, P., P. H. Du Toit, and A. Boshoff. 2010. "A Scholarly Reflection on My Whole Brain Assessment Style." Paper presented at the HELTASA (Higher Education Learning and Teaching Association South Africa) Conference: Higher Education Development: Academic Excellence, Opportunities and Challenges, 23-25 November, Tzaneen.

Steyn, T. M. 1998. "Graphical Exploration as an Aid to Mastering Fundamental Mathematical Concepts: An Instructional Model for Mathematics Practicals." MEd dissertation, University of Pretoria.

Steyn, T. M., and A. De Boer. 1998. "Mind Mapping as a Tool for Underprepared Students - A Report on Students Enrolled for the Extended Bsc Degree Course at the University Of Pretoria." South African Journal of Ethnology 21 (3): 125-131.

Tembe, C. 2011. "Exploring Professional Development Interventions for Improving the Teaching Practice of Primary School Teachers." PhD thesis, University of Pretoria.

Van der Watt, M. A. 2008. "The Integration of Critical Reflection as a Learning Strategy in the Training of Health Science Practitioners." PhD thesis, University of Pretoria.

Voges, A. 2005. "An Evaluative Analysis of a Whole Brain Learning Programme for Adults." PhD thesis, University of Pretoria.

Von Glasersfeld, E. 2001. "Radical Constructivism and Teaching." Prospects 31 (2): 161-173.

Von Maltitz, M. 2010. "Implementing Learning Style Flexibility for Change in Facilitating Learning in Higher Education." MEd dissertation, University of Pretoria.

Zimmerman, B. J., S. Bonner, and R. Kovach. 1996. Developing Self-Regulated Learners: Beyond Achievement to Self-Efficacy. Washington, DC: American Psychological Association.

Editorial history:

Paper received 21 August 2011

Revised version received 24 December 2011

Accepted 5 January 2012 